\title{
Processes Responsible for Electrical Breakdown Initiation in Commercial Indicator Gas Tube
}

\author{
ČEDOMIR A. MALUCKOV, University of Belgrade, \\ Technical faculty, Bor \\ Original scientific paper \\ MIODRAG K. RADOVIĆ, University of Niš \\ UDC: $621.382 .23: 621.372 .867$ \\ Faculty of Sciences and Mathematics, Niš \\ DRAGAN Đ. RADIVOJEVIĆ, University of Niš \\ Faculty of Sciences and Mathematics, Niš
}

The results of the commercial indictor gas tube investigation, by the time delay measuring method are presented in this paper. This tube is usually used as a indicator of many electrical appliances. The experimentally obtained time delay distributions for different voltages $(80 \mathrm{~V}, 90 \mathrm{~V}$ and $100 \mathrm{~V})$ and different relaxation times (from $1 \mathrm{~ms}$ to $20 \mathrm{~ms}$ ) are presented. It is shown that time delay distributions have Gaussian shape, and that used gas discharge tube has very small memory effect. Small memory effect indicates fast response, and consequently good characteristic for indicator tube.

Key words: Time delay distributions, commercial gas discharge tube, Gaussian probability plot

\section{INTRODUCTION}

Investigation of electrical breakdown in gases is important for describing processes and characteristics of gases as well as their practical applications [1]. The electrical breakdown time delay method for DC voltages, used in this experiment, gives very useful information about electrical breakdown, cathode effects, concentration of ions, electrons and neutral active particles in the afterglow [2], [3]. Mentioned method gives many useful informations about reliable of commercial gas components [4], [5], which are very significant in practical applications.

The electrical breakdown of gases is with a stochastic nature (as the result of the statistical behavior of the processes, which lead to it). The statistical theory of the electrical breakdown is described on the base of Townsend breakdown mechanism [6]. Breakdown criterion, according to Townsend theory (for small pressure and small overvoltages, when the influence of the space charge is neglected) is:

$$
\gamma\left[\exp \left(\int_{0}^{d} \alpha d x\right)-1\right]=1
$$

Author's address: Čedomir Maluckov, University of Belgrade, Technical Faculty, Bor, Vojske Jugoslavije 12

Paper received: 12.02.2014.

Paper accepted: 01.04.2014. where $\alpha$ is the primary ionization coefficient and $\gamma$ denote the effective secondary ionization coefficient (this coefficient includes all secondary processes).

One of the important electrical breakdown characteristics is the time delay $t_{D}$. That is time passed fro$\mathrm{m}$ the moment when the sufficient voltage $U_{W}$ is applied on the gas diode up to the electrical breakdown. The time delay consists of a statistical time delay $t_{S}$ and the discharge formative time $t_{F},\left(t_{D}=t_{S}+t_{F}\right)$ [7]. Statistical time delay $t_{S}$ represents time from the moment when voltage $U_{W}$ is applied until the occurrence of the initial electrons causing the breakdown. Statistical time delay is characterized with the exponential distribution [7]. The discharge formative time $t_{F}$ is the time from occurrence of initial electrons up to the electrical breakdown. The formative time delay is defined by the process of ionization and carrier multiplication in the gas, leading to the development of a low impedance conducting plasma. The formative time delay is characterized with the Gaussian distribution [8]-[10].

The electrical breakdown time delay distributions are investigated in many papers. In some of them, the time delay convolution model is developed [9], [10], [11]. This model the statistical and the formative time delays treated as sum of two independent random variables, with exponential (statistical time delay) and Gaussian (formative time delay) distribution. In contrary, in the reference [12] the authors claim in the ca- 
se of the small relaxation time (relaxation time $\tau$ represent time between two successive measurement, then is no voltage on the electrode of the gas tube), the mutual dependence of the statistical and the formation time delay, as well as, that for different relaxation times, total time delay has Gaussian, Gaussexponential and exponential log-normal shape. However the great number of papers indicated that formative time delay has not statistical behavior, and can be treated as constant value. In that case formative time delay value represent only shifted parameter in shifted exponential distribution.

In cases of $\mathrm{AC}$ voltage (i.e. when the voltage is varied in time) with low frequencies, the Townsend breakdown theory for DC voltage [6], [7] is applicable. However for higher frequencies, order of $\mathrm{kHz}$ and higher, Townsend breakdown theory is slightly modified. The Cobine-Easton theory [13] presents enlargement of Townsend theory, using the new coefficient which described voltage variation in time. This theory good describe the time delay in AC voltage at 100,400 and $800 \mathrm{kHz}$.

The aim of this work was to investigate the stationary current growing rate in indicator gas discharge tube, the breakdown time delay and to notify the regularity of these events, with accidental select diode.

\section{EXPERIMENT}

For measuring of the electrical breakdown time delay $t_{D}$, the gasmem $v 1.0$ system [14] is used. This system time delay treated as interval, between the moment when the $U_{W}$ voltage is applied (turned) on the gas tube and the moment when the desirable current $I_{0}\left(90 \%\right.$ of $I_{G}$, i.e. the total current through gas) appears in the gas. This measuring system can controlled relevant experiment parameters during the experiment relaxation time $\tau$, glowing time $t_{G}$ and current through the gas $I_{G}$ flows. During the time delay period $t_{D}$ period, the current in the gas is initially zero and then rapidly increases for a few ns until the gas breakdown occurs and the current reaches the $I_{G}$ value. During the $\tau$ period, there is no voltage $\left(U_{W}=\right.$ 0 ), but during the $t_{G}$ period, there is the $U_{W}$ voltage on the tube and the $I_{G}$ current flows through the tube. A diagram of the gasmem $v 1.0$ system is shown in figure 1.

The gasmem $v 1.0$ system is composed of three modules: (1) the control module (CM), (2) the analog switch module (ASM) and (3) the voltmeter module (VM). The CM is based on PIC18F4550 MCU that has internal hardware timers for time interval measurements and integrated USB2.0 module for interfacing with a personal computer (PC). A main fun- ction of the CM is to control the ASM that turns the gas tube voltage on or off, and to measure $t_{D}$. The CM is electrically isolated from the ASM by optocouplers. The VM is realized with PIC16F887 MCU whose internal 10-bit analog-to-digital (A/D) converter. It is used for the measurement of the current through the gas tube $\mathrm{I}_{\mathrm{G}}$ and for the adjustment of the desirable current for the stop signal (stop current, $\mathrm{I}_{0}$ ). The $\mathrm{I}_{\mathrm{G}}$ and $\mathrm{I}_{0}$ currents are measured by the voltage drops on the corresponding resistors. The VM incorporates an LCD display for displaying both $\mathrm{I}_{\mathrm{G}}$ and $\mathrm{I}_{0}$ (usually $\mathrm{I}_{0}$ $=0.9 \mathrm{I}_{\mathrm{G}}$ ). Electrical details of the measuring system gasmem v1.0 and the experimental procedures are described with more details in references [14].

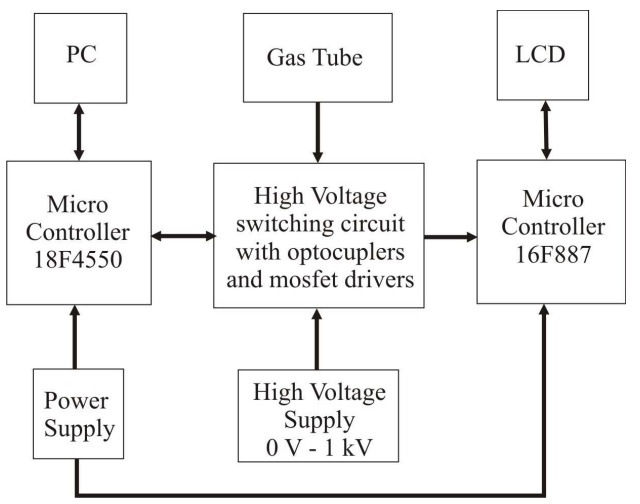

Figure 1 - The block diagram of the measured system gasmem v1.0 [14].

The maximal rise time of the desired voltage $\mathrm{U}_{\mathrm{W}}$ in the gasmem v1.0 system is $400 \mathrm{~ns}$ for $\mathrm{U}_{\mathrm{W}}=900 \mathrm{~V}$, and the the hardware limit of the $t_{D}$ measurement is about $800 \mathrm{~ns}$, which is absolutely sufficient for the main gas discharge conditions. The values of $\tau$ and $t_{\mathrm{G}}$ could be changed in the wide range from 1 to $2^{32} \mathrm{~ms}$ and ( $\approx 50$ days), respectively.

The measurements are done on the commercial indicator gas tube filled with neon. This tube is usually used as a indicator of many electrical appliances. The tube volume is $1 \mathrm{~cm}^{3}$, with $\mathrm{Cu}$ cylinder electrodes with parallel symmetry axis of cylinders. The current through measurement $\mathrm{I}_{\mathrm{G}}$ and glowing time $\mathrm{t}_{\mathrm{G}}$ were kept constant, i.e. $\mathrm{I}_{\mathrm{G}}=0.1 \mathrm{~mA}$ and $\mathrm{t}_{\mathrm{G}}=1 \mathrm{~s}$.

The randomness of the experimental data samples is checked by Wilcoxon or Mann-Whitney's test [5], [15]. The analysis shows that on both the confidence levels of $95 \%$ and $99 \%$ systematic trend is observed, confirming the randomness of data samples.

\section{RESULTS AND DISCUSSION}

The results of the investigation of the breakdown time delay distribution in commercial indicator tube are given in figure 2 , figure 3 , figure 4 and figure 5 . 


\subsection{The static breakdown voltage determination}

The static breakdown voltage of used gas tube is determined according to the definition where the static breakdown voltage is highest voltage at which breakdown did not take a place [16]. The estimations of the static breakdown are represented in figure 2 . Each point in this figure represents mean value of 100 consecutive and independent measurements. Thus, the estimated static breakdown voltage values are $U_{S}$ $=73 \mathrm{~V}$ as indicated in figure 2 .

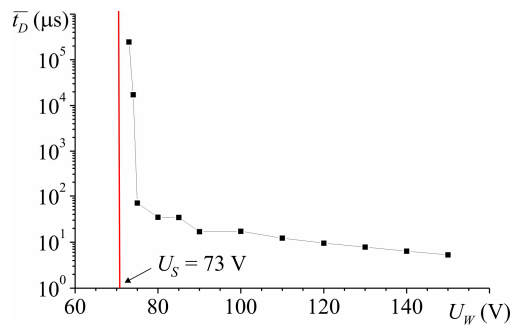

Figure 2 - Time delay in function of applied voltages.

\subsection{Memory curves}

The memory curves for the commercial indicator gas tube are given in figure 3 . Each point corresponds to the mean value of 100 measurements, for voltages $80 \mathrm{~V}, 90 \mathrm{~V}$ and $100 \mathrm{~V}$. From this figure it can be seen that memory effect exist up to approximately $8-9 \mathrm{~ms}$ for all voltages.

Usually, the memory curves have the expected shapes within three parts [17]: (1) the plateau region (for small values of relaxation time $\tau$ ); (2) the region with increase of time delay values, with increase of $\tau$, and (3) the saturation region. The shape of the memory curves is a consequence of different mechanisms which predominantly influence the secondary electron emission process from the cathode.

The memory curves presented in figure 3 are characterized with absence of plateau (1). This plateau of memory curve is a consequence of the presence of positive ions in the early afterglow (up to approximately $\tau \approx 80 \mathrm{~ms}$ for rare gases) [10], [11]. This shape of memory curves are probably caused by geometry typically for used indicator gas tube. Namely, very small volume of used tube cause quenching of the positive ions from previous discharge.

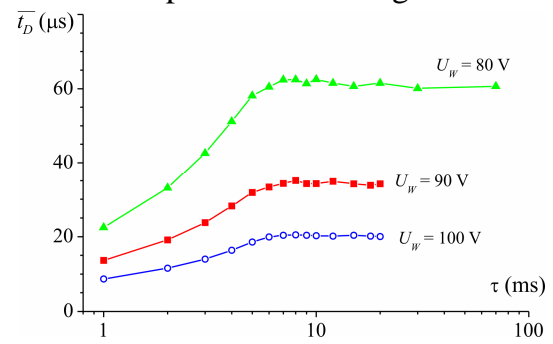

Figure 3 - Memory curves for indciated values of applied voltages.
The increase of $t_{D}$ values, up to $\tau \leq 9 \mathrm{~ms}$, as can be seen from figure 3 , is a consequence of the change in the mechanisms which dominate the process of the secondary electron emission. The emission of seconddary electrons from the cathode is mostly induced by neutral active states. However, in literature the character of neutral active states which are the most involved in memory effect in rear gases is doubtful. The neutral active states are ${ }^{3} P_{2}$ and ${ }^{3} P_{0}$ metastable atoms of rare gases [10], [11], [17], [18], which de-excite at the cathode surface and release the secondary electrons. On the contrary, in References [19] and [20] the remanent nitrogen atoms states initiate secondary electron emission. They exist in gas diodes after manufacturing. However, this dilemma does not influence the statistical approach applied in this paper, since it detects the secondary electrons without considering the mechanisms of their creation.

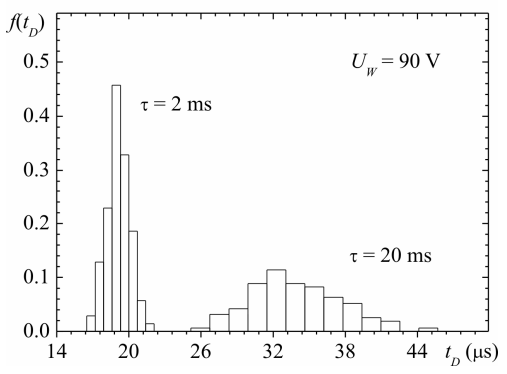

Figure 4 - Time delay density distributions for indicated applied voltages and relaxation times.

The third part of memory curve (from $\tau \geq 0.9 \mathrm{~ms}$ for $U_{W}=80 \mathrm{~V}, 90$ and $100 \mathrm{~V}$ ) represents the saturation of the time delay values. This saturation is a consequence of the significant decrease of concentrations of the neutral active particles. Thus, the number of secondary emitted electrons from the cathode is strongly reduced, and, hence, the breakdown is initiated by cosmic rays. Since the flux of cosmic rays during the experiment varies insignificantly, the breakdown time delay values are approximately constant [21].

\subsection{Time delay distributions}

Statistical analysis of the time delay distributions for commercial gas tube is performed using variation of relaxation time and voltages. Each of distribution is obtain from 1000 measurement. All distributions have a Gaussian like shape. Some of time delay distributions, for applied voltages $U_{W}=90 \mathrm{~V}$, and relaxation times $\tau=2 \mathrm{~ms}$ and $\tau=20 \mathrm{~ms}$, are presented in figure 4 . The time delay density distributions (both on the basis of 1000 independent and successive measurements) are given by histograms. The histograms are plotted according to the criterion that in the class with the maximum frequency should be around $20 \%$ of the measured values. Histograms are normalized dividing 
the relative frequencies of all classes by the class width $\Delta t_{D}$ in milliseconds.

From histograms, presented in figure 4, the Gaussian shape is clearly observed in the both of histograms, but with small asymmetry on the right side of distribution for relaxation time $\tau=20 \mathrm{~ms}$. In order to quantitative evaluation of similarity to Gaussian shape, all of distributions are presented in Gaussian probability diagrams. These diagrams are presented in figure 5. All Gaussian probability plots are fitted with straight lines. On all of diagrams, regression coefficients $R$ are given.

From the distributions presented in figure 5 it can be concluded that asymmetry of histograms decrease with increasing the relaxation time. This fact can be seen from regression coefficients $R$. As can be seen from figure 5, regression coefficients for smaller relaxation times have values closer to one. As can seen from figure 5, for relaxation time $\tau=2 \mathrm{~ms}$, regression coefficients has the values $R=0.99756, R=0.99957$ and $R=0.9994$ for applied voltages $U_{W}=80 \mathrm{~V}, 90 \mathrm{~V}$ and $100 \mathrm{~V}$, respectively. These values are very close to one, which indicated Gaussian distributions. Howe- ver, the values of regression coefficients decreased for bigger relaxation times values, and for relaxation times $\tau=20 \mathrm{~ms}$ regression coefficients reach the values $R=0.97531, R=0.9949$, and $R=9.96781$, for applied voltages $U_{W}=80 \mathrm{~V}, 90 \mathrm{~V}$ and $100 \mathrm{~V}$, respectively. Similar shape of density distributions are shown in reference [9], [10], [11] and [21]. This indicates that the dominant role, for relaxation times $\tau=$ $20 \mathrm{~ms}$, in breakdown initiation is played by positive ions remained from previous discharge. In this situations statistical time delay is much smaller than formative times, and total time delay distributions are determined by formative time delay distributions [9], [10], [11] and [21]. However, in used indicators gas discharge tube, electrode and tube geometry is totally different in order to geometry of gas tube from references [9], [10], [11] and [21]. Small volume of the diode, and characteristic electrode geometry caused faster metastable gas atoms recombination, and positive ions neutralization, and consequently very small memory effect. Namely, memory curves reach the saturation very fast (i.e. plateau which correspond to the third part of memory curve), for approximately $9 \mathrm{~ms}$.
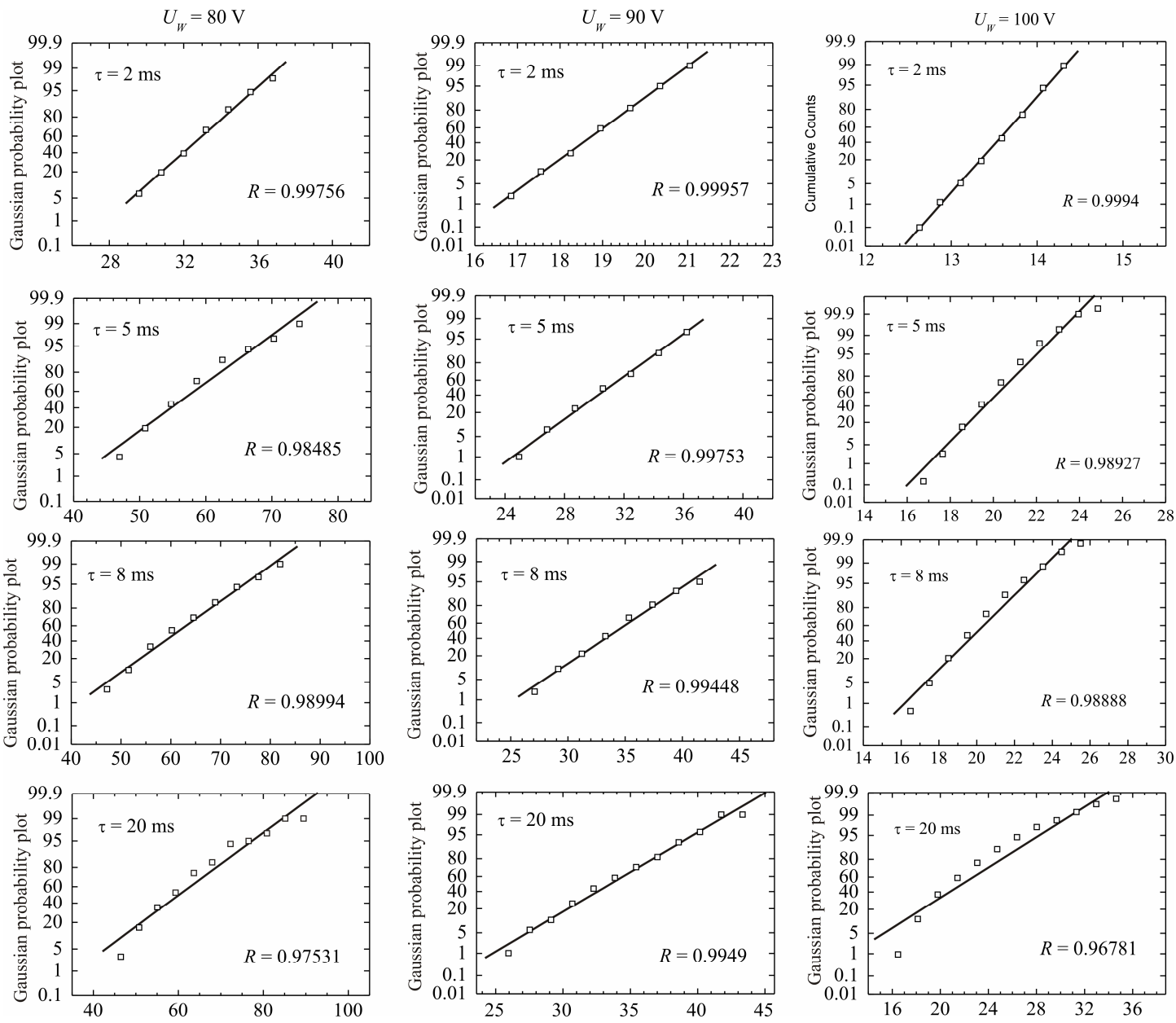

Figure 5 - Gaussian probability plots for indicated applied voltages $U_{W}$ and relaxation times $\tau$. 
This fact, i.e. fast saturation of memory curve cause very good applicability of used indicator gas discharge tubes. Namely, this fact is reason for very fast gas discharges after applying of voltages greater than static breakdown voltages. Fast appearance of light form indicator gas discharge tubes is the most important characteristic of used tubes.

\section{CONCLUSION}

The results of investigations of commercial indicators gas tube are presented in this paper. For these investigations the time delay method is used. The distributions are obtained on the base of 1000 independent and succesive measurements, for different relaxation times and applied voltages. The density distributions are presented in Gaussian probability diagramms. As the results of analysis analysis it can be concluded that distributions of time delay has the dominantly Gaussian shape.

The memory curves, for different applied voltages are investigations. The values of the time delay on the plateau, which correspond to the third part of memory curve, and the saturation of time delay values begin for the relaxation times $\tau=9 \mathrm{~ms}$. This shape of the third part of memory curves are caused by characteristic geometry of indicator gas discharge tube. The gas discharge tube geometry (small volume and typically electrode shape) caused faster metastable gas atoms recombination, and consequently very small memory effect.

The main purpose of indicator gas discharge tubes is their using as a indicator of many electrical appliances, i.e. in AC voltage circuit $\left(U_{E F F}=220 \mathrm{~V}, 50\right.$ $\mathrm{Hz}$ ). This voltage caused very fast gas discharges after applying of voltages, i.e. very fast response after applying voltage, and consequently the light appearance form used gas discharge tubes.

\section{ACKNOWLEDGEMENT}

This work was supported by the Ministry of Education and Science of the Republic of Serbia (Project 43011 and Project 43012).

\section{REFERENCES}

[1] Kristansen M., Guenter A. H., Plasma Applications, in: Electrical Breakdown and Discharges in Gases, Eds. Kunhart, E. E. Luessen L. H., Plenum Press, New York, 1983.

[2] Pejović M. M., Karamarković J. P. Ristić G. S., IEEE Trans. Plasma Sci. 26, p. 1733-1737, 1998.

[3] Pejović M., Mijović M., J. Tech. Phys. 58 p. 21242128, 1988. (in Russian)
[4] Pejović M. M., Pejović M. M., Stanković K. Đ., Jpn. Journal of Appl. Phys. 50, 086001 (2011).

[5] Maluckov Č. A., Radović M. K., Rančev S.A., Ristić G. S., Karamarković J. P., Rom. Rep. Phys. 65 (4), p. 1373-1383, 2013.

[6] Llewellyn-Jones F., The Development of Theories of the Electrical Breakdown of Gases, in: Electrical Breakdown and Discharges in Gases, Eds. Kunhart E. E., Luessen L. H., Plenum Press, New York (1983).

[7] Morgan C. G., Irradiation time lags, in: Electrical Breakdown of Gases, Eds. Meek J. M., Craggs J. D., John Wiley \& Sons, Chichester, 1987.

[8] Moreno J., Zambra M., Favre M., IEEE Trans. Plasma Sci. 30, p. 417-422, 2002.

[9] Maluckov Č. A., Karamarković J. P., Radović M. K., IEEE Trans. Plasma Sci. 31, p. 1344-1348, 2003.

[10] Maluckov Č. A., Karamarković J. P., Radović M. K., Pejović M. M., Phys. Plasmas 11, p. 5328-5334, 2004.

[11] Maluckov Č. A., Karamarković J. P., Radović M. K., Pejović M. M., Phys. Plasmas 13, 083502, 2006.

[12] Marković V. Lj., Gocić S. R. Stamenković S. N., J. Phys. D: Appl. Phys. 42, 015207, 2009.

[13] Sobota A., Kanters J. H. M., Veldhuizen E. M., Manders F, Haverlag M., J. Phys. D: Appl. Phys., 44, 135203, 2011.

[14] Todorović M., Vasović N. D., Ristić G. S., Meas. Sci. Technol. 23, 015901, 2012.

[15] Wackerly D. D., Mendenhall W. III, Scheaffer R.L., Mathematical Statistics with Applications, Duxbury Press, Belmont, 1996.

[16] Radović M. K., Stepanović O. M., Maluckov Č. A., J. Phys. D, Appl. Phys, 31, p. 1206-1211, 1997.

[17] Pejović M. M., Ristić G.S., Karamarković J. P., J. Phys. D: Appl. Phys. 35, R. 91-103, 2002.

[18] Pejović M. M., Ristić G.S., Phys. Plasmas 9, p. 364371, 2002.

[19] Kudrle V., LeDuc E., Faitare M., J. Phys. D: Appl. Phys. 32, p. 2049-2056, 1999.

[20] Marković V. Lj., Gocić S. R., Stamenković S. N., Petrović Z. Lj., Phys. Plasmas 12, 073502, 2005.

[21]Spasić I. V., Radović M. K., Pejović M. M., Maluckov Č. A., J. Phys. D: Appl. Phys. 36, p. 2515-2520, 2003. 


\section{REZIME}

\section{ISPITIVANJE KARAKTERISTIKA KOMERCIJALNE GASNE TINJALICE METODOM MERENJA VREMENA KAŠNJENJA}

U radu su prikazani rezultati ispitivanja komercijalne gasne diode, korišćenjem metode merenja vremena kašnjenja. Ova gasna dioda se najčešće koristi kao indikator uključenosti u mnogim električnim uređajima. Eksperimentalno su dobijene raspodele vremena kašnjenja za različite napone $(80 \mathrm{~V}, 90 \mathrm{~V}$ and $100 \mathrm{~V}) \mathrm{i}$ različita vremena relaksacije (od $1 \mathrm{~ms}$ do $20 \mathrm{~ms}$ ). Pokazano je raspodele imaju gausovski oblik, kao i da memorijske krive korišćene gasne diode imaju veoma mali memorijski efekat, koji ukazuje na veoma kratko vreme do proboja nakon veoma dugog vremena relaksacije, $i$ shodno tome dobru karakteristiku za indikatorske gasne diode.

Ključne reči: Raspodele vremena kašnjenja, komercijalne gasne diode, dijagram Guasovih verovantoća 